\title{
Sputtering Power Induced Physical Property Variation of Nickel Oxide Films by Radio Frequency Magnetron Sputtering
}

\author{
Yang Zhao ${ }^{a}$, Hui Wang ${ }^{a}$, Fan Yang ${ }^{b}$, Zhiyuan Wang ${ }^{a}$, Jingjie Li ${ }^{a}$, Yutao Gao ${ }^{a}$, Zhennan Feng ${ }^{a}$, \\ Xinzhong Li ${ }^{a}$, Zhiqiang Zhen ${ }^{a}$ \\ ${ }^{a}$ School of Physics and Engineering, Henan Key Laboratory of Photoelectric Energy Storage Materials \\ and Applications, Henan University of Science and Technology, 263 Kaiyuan Avenue, Luoyang 471003, \\ People's Republic of China \\ ${ }^{b}$ Jilin Provincial Key Laboratory of Architectural Electricity \& Comprehensive Energy Saving, \\ School of Electrical Engineering and Computer, Jilin Jianzhu University, Changchun, 130118, \\ People's Republic of China
}

Received: September 20, 2017; Revised: December 04, 2017; Accepted: December 30, 2017

\begin{abstract}
$\mathrm{NiO}$ thin films were deposited on Si and Corning 1737 glass substrates using radio frequency (rf) magnetron sputtering system. The physical properties of $\mathrm{NiO}$ films under different sputtering power were thoroughly studied. The XRD results indicated that as-prepared $\mathrm{NiO}$ films with the sputtering power above $100 \mathrm{~W}$ developed only (200) preferred orientation. The AFM results showed that the $\mathrm{NiO}$ films were composed of different-size $\mathrm{NiO}$ nano-grains and the grain size increased with increasing the sputtering power. The samples marked A-E under the sputtering power of 80, 100, 120, 140 and $160 \mathrm{~W}$ have optical band gap values of $3.70,3.65,3.50,3.45$ and $3.44 \mathrm{eV}$, respectively. Comparatively, the controllable electrical properties of the films could be achieved by the variation of crystal quality arises from the sputtering power.
\end{abstract}

Keywords: Nickel oxide, Magnetron sputtering, Sputtering power, Structure properties.

\section{Introduction}

Recently, substantive research efforts have been made on Nickel oxide (NiO) materials due to its excellent chemical stability, magnetic, electric and optical properties, which are widely applied in the fields of functional chemical sensor layers ${ }^{1}$, antiferromagnetic materials ${ }^{2}$, ultraviolet (UV) transparent conducting films ${ }^{3}$ and cathode material for electrochromic display devices ${ }^{4}$. Especially, the attractiveness of $\mathrm{NiO}$ material lies in the fact that the $\mathrm{NiO}$ films has an natural p-type conductivity and low preparation costs compared to the high-quality p-type $\mathrm{ZnO}$ and $\mathrm{GaN}$ materials, which are difficult to achieve due to the less stability and high resistance ${ }^{5-10}$. Recently, Patel et al. ${ }^{11}$ fabricated $\mathrm{NiO} /$ $\mathrm{ZnO}$ heterojunction on plastic substrate for ultraviolet photodetector applications. Baraik et al. ${ }^{12}$ grew the $\mathrm{NiO}$ epilayer on $\mathrm{GaN}$ templates to investigate the band alignment properties for the $\mathrm{NiO} / \mathrm{GaN}$ heterostructure light-emitting diode applications. And Shi et al. ${ }^{13}$ used Mg-doped NiO as the p-type layer to design high-efficiency and air stable perovskite quantum dots heterostructure light-emitting diodes. The NiO film has been recognized as a promising p-type conductive material for the fabrication of heterojunction light emitting diodes and laser diodes. As well known, many methods have been used for preparing $\mathrm{NiO}$ films, which involves magnetron sputtering ${ }^{14}$, vacuum evaporation ${ }^{15}$, sol-gel deposition ${ }^{16}$, pulsed laser deposition ${ }^{17}$, metal organic

*e-mail: 1wc9442@126.com chemical vapor deposition (MOCVD) ${ }^{18}$, etc. Among these methods, magnetron sputtering has been most widely useful technique due to high deposition rates, uniformity over large areas of the substrates and easy control over the composition of the deposited films. Generally, the oxide film properties are dependent on various deposition process parameters such as substrate temperature, sputtering pressure, oxygen partial pressure and doping concentration ${ }^{19-21}$. In this work, we report on the fabrication of p-type $\mathrm{NiO}$ films on $\mathrm{Si}$ and Corning 1737 glass substrates by radio frequency magnetron sputtering system. The effects of sputtering power on the crystal structure, surface morphology, optical and electrical characteristics of $\mathrm{NiO}$ films are investigated.

\section{Experiments}

The NiO films were deposited on $\mathrm{Si}$ and Corning 1737 glass substrates by radio frequency magnetron sputtering system from a $\mathrm{NiO}$ target of $99.99 \%$ purity at different sputtering power. The sputtering powers were adjusted to be 80,100 , 120,140 and $160 \mathrm{~W}$ respectively corresponding to the $\mathrm{NiO}$ samples marked as (A)-(E), respectively. The deposition was performed in a mixture of $\mathrm{Ar}$ and $\mathrm{O}_{2}$ atmosphere under $\mathrm{Ar} /$ $\mathrm{O}_{2}$ flow rate ratio of 1:1. The distance between the target and the substrate was approximately $7 \mathrm{~cm}$. Sputtering deposition was performed at room temperature and the pressure in vacuum chamber was kept $1.0 \mathrm{~Pa}$. The thickness of the $\mathrm{NiO}$ film was about $200 \mathrm{~nm}$. 
The crystal structures of $\mathrm{NiO}$ samples were measured by Ultima IV X-ray Diffracrometer (XRD) in a $\theta-2 \theta$ configuration with $\mathrm{Cu} K \alpha$ radiation $(\lambda=0.154 \mathrm{~nm})$. The surface morphologies were observed by Veeco atomic force microscopy (AFM). The characteristics of UV transmission were investigated by SHIMADZU UV-3600 Spectrophotometer. In addition, X-ray photoelectron spectroscopy (XPS) (SPECS XR50) was carried out to determine the composition and nickel valence state in the $\mathrm{NiO}$ films. And the electrical properties of the NiO samples were measured by ACCENT HL5500PC Hall system. All the measurements were performed at room temperature.

\section{Results and Discussion}

The crystal structure characteristics of the NiO samples A-E deposited on Si substrates under different sputtering power were shown in Fig. 1. It was noted that the XRD pattern of $\mathrm{NiO}$ sample grown at lower sputtering power revealed a weak and a strong diffraction peak, located at $\sim 37.3^{\circ}$ and $42.8^{\circ}$, which was corresponding to the $\mathrm{NiO}$ (111) and $\mathrm{NiO}$ (200) reflections, respectively. Further increasing the sputtering power above $100 \mathrm{~W}$, the $\mathrm{NiO}$ (111) peak had completely disappeared and only $\mathrm{NiO}$ (200) peak could be observed. This was probably due to the fact that most of the sputtered $\mathrm{NiO}$ particles did not have enough kinetic energy to migrate to the suitable nucleation sites under lower sputtering power. Nevertheless, more crystallites could move to the substrate surface and grow in the structure under higher sputtering power ${ }^{22}$. Moreover, it was noted that the intensity of $\mathrm{NiO}$ (200) diffraction exhibited an increasing trend as the sputtering power increased. However, the intensity of the diffraction decreased heavily over the sputtering power of $160 \mathrm{~W}$, which might be attributed to the worse integrality of the films under the condition of excessive sputtering power. This could be seen clearly from the result found in AFM images as shown in Fig.2.

The 3D surface morphologies of the NiO samples deposited on Si substrates under different sputtering power were shown in Fig. 2. It was evident that the surface morphology of the $\mathrm{NiO}$ films was influenced by the sputtering power. On the one hand, it could be seen that the NiO samples had a columnar structure with growth perpendicular to the film surface and the grain size of the $\mathrm{NiO}$ samples increased significantly with increasing sputtering power. On the other hand, the surface of the $\mathrm{NiO}$ films became rough and ununiform at the sputtering power above $160 \mathrm{~W}$, which indicated that excessive sputtering power would destroy the integrality of the films. This might be attributed to fact that the sputtering rate would increase heavily under higher sputtering power, which could induce the secondary sputtering and decrease the kinetic energy of the sputtered $\mathrm{NiO}$ particles ${ }^{23}$. Moreover, the RMS roughness of the $\mathrm{NiO}$ samples grown at 80,100 , 120,140 and $160 \mathrm{~W}$, calculated from $3 \times 3 \mathrm{um}^{2}$ AFM scans, were $3.7,4.1,5.9,7.8$ and $13.1 \mathrm{~nm}$, respectively.

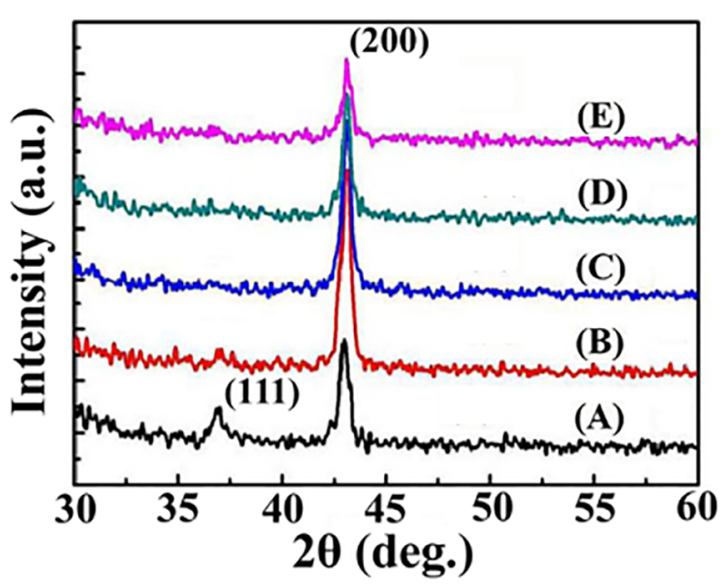

Figure 1. XRD spectra of the $\mathrm{NiO}$ samples deposited on $\mathrm{Si}$ substrates at different sputtering power: (A) $80 \mathrm{~W}$, (B) $100 \mathrm{~W}$, (C) $120 \mathrm{~W}$, (D) $140 \mathrm{~W}$ and (E) $160 \mathrm{~W}$

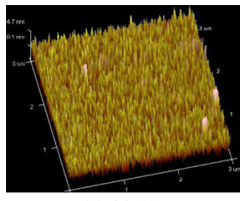

(a) $80 \mathrm{~W}$

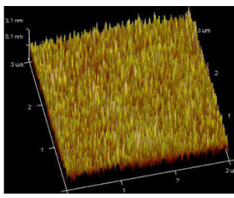

(b) $100 \mathrm{~W}$

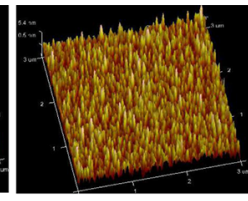

(c) $120 \mathrm{~W}$

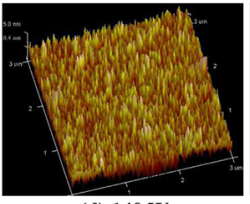

(d) $140 \mathrm{~W}$

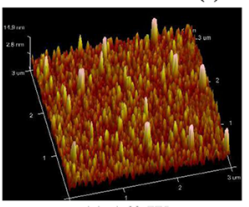

(e) $160 \mathrm{~W}$
Figure 2. 3D morphology of the AFM images $\left(3 \times 3 u^{2}\right)$ of the $\mathrm{NiO}$ samples deposited on $\mathrm{Si}$ substrates at different sputtering power

The optical properties of the NiO samples deposited on Corning 1737 glass substrates were investigated by the transmittance and optical absorption measurements as shown in Fig. 3. It could be seen in Fig. 3(a) that the $\mathrm{NiO}$ samples had good transmittance characteristics in the visible range with an average transmittance about $80 \%$. However, the transmittance fell rapidly in the UV region near the absorption edge, which indicated that the $\mathrm{NiO}$ films could be a good candidate for the fabrication of UV detectors. Moreover, it was noted that the transmittance exhibited an increasing trend with the increase in sputtering power. This was probably attributed to the decrease of the interstitial atoms in non-stoichiometric $\mathrm{NiO}$ films, which would cause to scatter or absorb the incident light ${ }^{24}$. Furthermore, the optical band gaps of the $\mathrm{NiO}$ samples were detected by the optical absorption measurement as shown in Fig. 3(b). The optical band gap could be estimated according to the relation (1):

$$
a h v=A\left(h v-E_{g}\right)^{1 / 2}
$$

Where A is a constant and hv is the photon energy. The optical band gaps of the $\mathrm{NiO}$ samples A-E were about 3.70, $3.65,3.50,3.45$ and $3.44 \mathrm{eV}$, respectively, which were all 


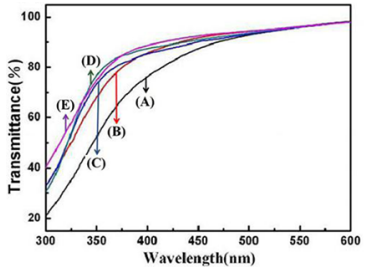

(a)

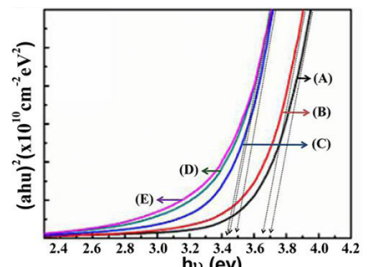

(b)
Figure 3. (a) Transmittances of $\mathrm{NiO}$ samples A-E deposited on Corning 1737 glass substrates at different sputtering power. (b) Optical absorption spectra of $\mathrm{NiO}$ samples grown at different sputtering power. The dotted line is a guide to the eye

larger than that of $\mathrm{ZnO}(3.3 \mathrm{eV})$ or $\mathrm{GaN}(3.4 \mathrm{eV})$ materials. It could be noticed that the optical band gap shifted towards lower energy with the increment of the sputtering power. This was probably attributed to the band tailing effect by the non-stoichiometric composition and the crystallinity improvement ${ }^{25}$.

The NiO samples were also investigated by XPS measurement as shown in Fig. 4. The pattern of the Ni $2 p$ core levels peaked at 854.5 and 873.1 corresponding to the $\mathrm{Ni} 2 \mathrm{p} 3 / 2$ and $\mathrm{Ni} 2 \mathrm{p} 1 / 2$ states of the Ni-O bond, respectively ${ }^{26}$. Besides, the shake-up structures of the $\mathrm{NiO}$ films (indicated by the arrows) could be observed and no extra substances were detected in the XPS spectra. Moreover, the atomic ratio of $\mathrm{Ni}$ to $\mathrm{O}$ for the $\mathrm{NiO}$ samples deposited at $120 \mathrm{~W}$ was calculated to be nearly $1: 1$, which indicated that the oxidation state of $\mathrm{Ni}$ was +2 in the as-grown $\mathrm{NiO}$ compounds ${ }^{27}$.

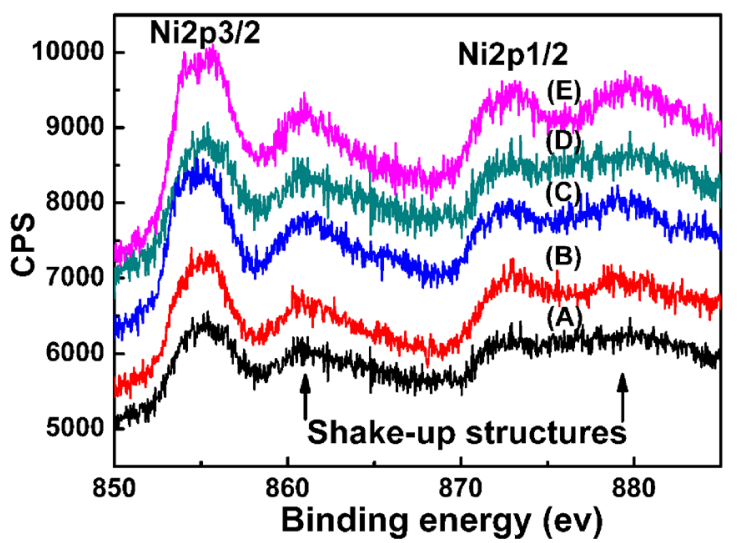

Figure 4. Ni 2 p XPS spectra of the NiO samples grown at different sputtering power

The Hall results of the $\mathrm{NiO}$ samples deposited at different sputtering power were shown in Table 1 . All of the five samples exhibited p-type characteristics and the carrier concentration varied from $9.638 \times 10^{20}$ to $1.539 \times 10^{19} \mathrm{~cm}^{-3}$, as the sputtering power increased. In addition, the mobility of the $\mathrm{NiO}$ films increased from 0.027 to $0.284 \mathrm{~cm}^{2} / \mathrm{v}$.s with the increase in sputtering power. According to the earlier reports, the existence of $\mathrm{Ni}^{2+}$ would cause the $\mathrm{NiO}$ material to exhibit p-type conductivity even for stoichiometric composition ${ }^{28}$.
Consequently, the increase of the hole mobility was probably ascribe to the improvements of the $\mathrm{NiO}$ crystalline qualities and the decline of the hole concentration should be attributed to the decrease of $\mathrm{Ni}^{2+}$ vacancies ${ }^{29}$.

Table 1. The Hall measurement results of the NiO samples A-E deposited at different sputtering power

\begin{tabular}{cccc}
\hline Sample & $\begin{array}{c}\text { Resistivities } \\
(\Omega \cdot \mathrm{cm})\end{array}$ & $\begin{array}{c}\text { Mobility } \\
\left(\mathrm{cm}^{2} / \mathrm{v} \cdot \mathrm{s}\right)\end{array}$ & $\begin{array}{c}\text { Hole } \\
\text { Concentration } \\
\left(\mathrm{cm}^{-3}\right)\end{array}$ \\
\hline (A) & 2.428 & 0.027 & $+9.638 \times 10^{20}$ \\
$(\mathrm{~B})$ & 1.847 & 0.036 & $+9.442 \times 10^{19}$ \\
$(\mathrm{C})$ & 1.806 & 0.181 & $+1.917 \times 10^{19}$ \\
$(\mathrm{D})$ & 1.429 & 0.284 & $+1.539 \times 10^{19}$ \\
(E) & 1.809 & 0.201 & $+1.853 \times 10^{19}$ \\
\hline
\end{tabular}

\section{Conclusion}

In conclusion, the strong dependence of the characteristics of $\mathrm{NiO}$ films fabricated by magnetron sputtering on the sputtering power was demonstrated. The experimental results revealed that high crystal quality $\mathrm{NiO}$ films could be obtained by increasing the sputtering power. Hall measurement results illustrated that all the $\mathrm{NiO}$ films exhibited p-type conductivity and its mobility increased with increasing sputtering power. This study indicates that the optimum electrical conductivity and optical properties of $\mathrm{NiO}$ films could be achieved at appropriate sputtering power. It is believed that the $\mathrm{NiO}$ films could be a promising p-type candicate material in the fabrication of heterojunction light emitting diodes with other n-type wide band gap semiconductors.

\section{Acknowledgment}

This work was supported by the National Natural Science Foundation of China under Grant numbers 61674052 and 11404097.

\section{References}

1. Kumagai H, Matsumoto M, Toyoda K, Obara M. Preparation and characteristics of nickel oxide thin film by controlled growth with sequential surface chemical reactions. Journal of Materials Science Letters. 1996;15(12):1081-1083.

2. Fujii E, Tomozawa A, Torii H, Takayama R. Preferred Orientations of NiO Films Prepared by Plasma-Enhanced Metalorganic Chemical Vapor Deposition. Japanese Journal of Applied Physics. 1996;35(Pt 2 3A):L328-L330.

3. Scharber MC, Mühlbacher D, Koppe M, Denk P, Waldauf C, Heeger AJ, et al. Design Rules for Donors in Bulk-Heterojunction Solar Cells-Towards 10\% Energy-Conversion Efficiency. Advanced Materials. 2006;18(6):789-794.

4. Kitao M, Izawa K, Urabe K, Komatsu T, Kuwano S, Yamada S. Preparation and Electrochromic Properties of RF-Sputtered 
NiOx Films Prepared in $\mathrm{Ar} / \mathrm{O}_{2} / \mathrm{H}_{2}$ Atmosphere Japanese Journal of Applied Physics. 1994,33(Pt 1 12A):6656-6662.

5. Shih YT, Wu MK, Li WC, Kuan H, Yang JR, Shiojiri M, et al. Amplified spontaneous emission from $\mathrm{ZnO}$ in $\mathrm{n}-\mathrm{ZnO} / \mathrm{ZnO}$ nanodots- $\mathrm{SiO}_{2}$ composite/p-AlGaN heterojunction light-emitting diodes. Nanotechnology. 2009;20(16):165201.

6. Zhang JY, Zhang QF, Deng TS, Wu JL. Electrically driven ultraviolet lasing behavior from phosphorus-doped $\mathrm{p}-\mathrm{ZnO}$ nanonail array/n-Si heterojunction. Applied Physics Letters. 2009;95(21):211107.

7. Shi ZF, Sun XG, Wu D, Xu TT, Zhuang SW, Tian YT, et al. High-performance planar green light-emitting diodes based on a PEDOT:PSS $/ \mathrm{CH}_{3} \mathrm{NH}_{3} \mathrm{PbBr}_{3} / \mathrm{ZnO}$ sandwich structure. Nanoscale. 2016;8(19):10035-10042.

8. Zhao Y, Wang H, Wu GG, Jing Q, Gao FB, Li WC, et al. Near infrared electroluminescence from $\mathrm{n}-\mathrm{InN} / \mathrm{p}-\mathrm{NiO}$ heterojunction light-emitting diode. Materials Research Express. 2015;2(3):035901.

9. Wang H, Zhang BL, Wu GG, Wu C, Shi ZF, Zhao Y, et al. Properties of p-NiO/n-GaN Diodes Fabricated by Magnetron Sputtering. Chinese Physics Letters. 2012;29(10):107304.

10. Tay CB, Chua SJ, Loh KP. Stable p-Type Doping of ZnO Film in Aqueous Solution at Low Temperatures. The Journal of Physical Chemistry C. 2010;114(21):9981-9987.

11. Patel M, Kim J. Transparent $\mathrm{NiO} / \mathrm{ZnO}$ heterojunction for ultra-performing zero-bias ultraviolet photodetector on plastic substrate. Journal of Alloys and Compounds. 2017;729:796-801.

12. Baraik K, Singh SD, Kumar Y, Ajimsha RS, Misra P, Jha SN, et al. Epitaxial growth and band alignment properties of $\mathrm{NiO} / \mathrm{GaN}$ heterojunction for light emitting diode applications. Applied Physics Letters. 2017;110(19):191603.

13. Shi ZF, Li Y, Zhang YT, Chen YS, Li XJ, Wu D, et al. HighEfficiency and Air-Stable Perovskite Quantum Dots Light-Emitting Diodes with an All-Inorganic Heterostructure. NanoLetters. 2017;17(1):313-321.

14. Park JW, Park JW, Kim DY, Lee JK. Reproducible resistive switching in nonstoichiometric nickel oxide films grown by rf reactive sputtering for resistive random access memory applications. Journal of Vacuum Science \& Technology A: Vacuum, Surfaces, and Films. 2005;23(5):1309-1313.

15. Sasi B, Gopchandran KG, Manoj PK, Koshy P, Prabhakara Rao $\mathrm{P}$, Vaidyan VK. Preparation of transparent and semiconducting NiO films. Vacuum. 2003;68(2):149-154.

16. Korosec RC, Bukovec P. Sol-Gel Prepared NiO Thin Films for Electrochromic Applications. Acta Chimica Slovenica. 2006;53(2):136-147.
17. Tachiki M, Hosomi T, Kobayashi T. Room-Temperature Heteroepitaxial Growth of NiO Thin Films using Pulsed Laser Deposition. Japanese Journal of Applied Physics. 2000;39(Pt 1 4A):1817-1820.

18. Wang H, Zhao Y, Li XZ, Wu C, Dong X, Ma Y, et al. Nickel flux induced effects on structural and optical properties of $\mathrm{NiO}$ films fabricated by PA-MOCVD. Vacuum. 2015;119:77-80.

19. Reddy YAK, Reddy AS, Reddy PS. Substrate Temperature Dependent Properties of Cu Doped NiO Films Deposited by DC Reactive Magnetron Sputtering. Journal of Materials Science \& Technology. 2013;29(7):647-651.

20. Ramana CV, Mudavakkat VH, Bharathi KK, Atuchin VV, Pokrovsky LD, Kruchinin VN. Enhanced optical constants of nanocrystalline yttrium oxide thin films. Applied Physics Letters. 2011;98(3):031905.

21. Atuchin VV, Kruchinin VN, Wong YH, Cheong KY. Microstructural and optical properties of ZrON/Si thin films. Materials Letters. 2013;105:72-75.

22. El-Kadry N, Ashour A, Mahmoud SA. Structural dependence of d.c. electrical properties of physically deposited CdTe thin films. Thin Solid Films. 1995;269(1-2):112-116.

23. Zhao Y, Wang H, Wu C, Shi ZF, Gao FB, Li WC, et al. Structures, electrical and optical properties of nickel oxide films by radio frequency magnetron sputtering. Vacuum. 2014;103:14-16.

24. Yang M, Shi Z, Feng JH, Pu HF, Li GF, Zhou J, et al. Copper doped nickel oxide transparent p-type conductive thin films deposited by pulsed plasma deposition. Thin Solid Films. 2011;519(10):3021-3025.

25. Dutta T, Gupta P, Gupta A, Narayan J. Effect of Li doping in $\mathrm{NiO}$ thin films on its transparent and conducting properties and its application in heteroepitaxial p-n junctions. Journal of Applied Physics. 2010;108(8):083715.

26. Shu HM, Xie JM, Xu H, Li HM, Gu Z, Sun GS, et al. Structural characterization and photocatalytic activity of $\mathrm{NiO} / \mathrm{AgNbO}_{3}$. Journal of Alloys and Compounds. 2010;496(1-2):633-637.

27. Wang H, Zhao Y, Wu C, Dong X, Zhang BL, Wu GG, et al. Ultraviolet electroluminescence from $\mathrm{n}-\mathrm{ZnO} / \mathrm{NiO} / \mathrm{p}-\mathrm{GaN}$ lightemitting diode fabricated by MOCVD. Journal of Luminescence. 2015;158:6-10.

28. Jarzebski ZM. Oxide Semiconductors. Oxford: Pergamon Press; 1973.

29. Chen SC, Kuo TY, Sun TH. Microstructures, electrical and optical properties of non-stoichiometric p-type nickel oxide films by radio frequency reactive sputtering. Surface and Coatings Technology. 2010;205(Suppl 1):S236-S240. 